\section{A cartografia no/do fazer pedagógico: saberes e práticas no
espaço escolar \\ A cartografia no/do fazer pedagógico: saberes e práticas no
espaço escolar}

Dent

Resumo: Este texto contempla uma discussão sobre a Cartografia Escolar e o uso de recursos cartográficos no processo de ensino-aprendizagem de conceitos e temas geográficos, no âmbito dos anos iniciais da Educação Básica. Trata-se de um recorte de uma pesquisa realizada em três escolas públicas localizadas no bairro Queimadinha, na cidade de Feira de Santana - Bahia, no ano de 2010. O principal objetivo foi: verificar como os professores utilizam os recursos cartográficos para ensinar e aprender a Geografia. Desse modo, este estudo possibilitou contemplar uma reflexão sobre os conceitos cartográficos e o uso dos seus instrumentos por professores que lecionam Geografia nas escolas públicas de Ensino Fundamental I e suas influências no espaço da sala de aula, tendo a observação, questionários e entrevistas como técnicas/procedimentos metodológicos na referida pesquisa.

\section{The cartography in the pedagogy: knowledge and practice in the school}

\begin{abstract}
This text provides a discussion of the cartography in the school and the use of cartographic resources in the teaching and learning of geographical concepts and themes, within the early years of basic education. This is part of a research conducted in three public schools in the neighborhood of Queimadinho in the city of Feira de Santana - Bahia, in 2010. The main objective was to determine how teachers use the cartographic resources for teaching and learning geography. Thus, this study made it possible to contemplate a reflection about cartographic concepts and the use of their instruments for geography teachers who teach in public schools in elementary school I and its influences within the classroom, being the observation, questionnaires and interviews the methodological procedures used in the mentioned research.
\end{abstract}

\section{Ricardo Bahia Rios* Deuzimar da Conceição de Souza** \\ Jussara Fraga Portugal ${ }^{* * *}$ Simone Santos de Oliveira $^{\star \star * \star}$}

* Doutorando e Mestre em Geografia pela Universidade Federal da Bahia. Professor de Cartografia do Instituto Federal da Bahia-Campus Salvador.

** Licenciado em Geografia pela Universidade do Estado da Bahia. Professor da rede pública municipal de Feira de SantanaBA.

${ }^{* * *}$ Doutoranda e Mestre em Educação e Contemporaneidade - PPGEduC/UNEB. Professora Assistente da Universidade do Estado da Bahia - UNEB, Campus XI.

${ }^{* * * *}$ Mestre em Desenho, Cultura e Interatividade - PPGDCI/UEFS. Professora Substituta da Universidade do Estado da Bahia - UNEB, Campus XI.

Palavras-chave: Cartografia Escolar; Linguagem Cartográfica; Professoras do Ensino Fundamental

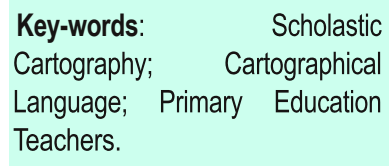




\section{Cartografando a pesquisa: Uma introdução}

A pertinência deste trabalho inscreve-se em um movimento de investigação que adota a abordagem qualitativa, tendo a observação, o questionário e a entrevista semi-estruturada como as suas principais técnicas de recolha de dados. Trata-se de uma discussão decorrente de uma pesquisa intitulada "Alfabetização cartográfica nos anos iniciais: um estudo de caso nas escolas públicas do bairro Queimadinha na cidade de Feira de Santana-BA" sobre o ensino da Cartografia em três escolas públicas, sendo duas municipais e uma estadual, tendo como colaboradores seis professores que exercem a docência nesses espaços formativos, no $5^{\circ}$ Ano do Ensino Fundamental I. O principal objetivo que norteou a referida investigação foi analisar as práticas de alfabetização cartográfica empreendidas pelas professoras.

A escolha de professores que lecionam no $5^{\circ}$ Ano foi intencional porque se compreende que ao final desta primeira etapa de escolarização, a escola deve garantir a aprendizagem de noções básicas da Cartografia sistemática e temática.

Discutir a Cartografia escolar, analisar como os seus conceitos estão sendo formulados em sala de aula por professores que lecionam a disciplina Geografia, implica concebê-los como sujeitos, atores e autores no processo de ensino e aprendizagem da criança.

A alfabetização cartográfica nas séries iniciais "permite e aponta diferentes práticas para que a criança aprenda simultaneamente a pensar e a ler o espaço" (NOGUEIRA, 2009, p. 16), onde tal alfabetização acontece quando a criança consegue reconhecer os lugares e identificar as paisagens. Sendo assim,

A alfabetização cartográfica é uma proposta de transposição didática da Cartografia básica e da Cartografia temática para usuários do ensino fundamental, em que se aborde o mapa do ponto de vista metodológico e cognitivo. Ela é uma proposta para que os alunos vivenciem as funções do cartógrafo e do geógrafo, transitando do nível elementar para o nível avançado, tornando-se leitores eficientes de mapas. $O$ aluno-mapeador desenvolve habilidades necessárias ao geógrafo investigador: observação, levantamento, tratamento, análise e interpretação de dados. 0 espaço lido e mapeado é ressignificado (PASSINI, 2007, p. 147).

Neste trabalho buscamos, então, contemplar uma reflexão sobre esses conceitos cartográficos e o uso dos seus instrumentos por professores que lecionam Geografia nas classes dos anos iniciais das escolas públicas do bairro Queimadinha em Feira de Santana (BA) e suas influências no espaço da sala de aula.

Para atingir o objetivo e contemplar o objeto desta investigação recorremos aos estudos de Castrogiovanni (2000), o qual destaca que a Cartografia oferece compreensão espacial dos fenômenos e serve de instrumento de conhecimento, domínio e controle de um território, assim como documentos oficiais como os Parâmetros Curriculares Nacionais (1998) que nos remete ao conceito de Cartografia como um conhecimento que vem se desenvolvendo desde a PréHistória até os dias de hoje e que, por intermédio da Linguagem Cartográfica, se torna possível sintetizar informações, expressar conhecimentos. Oliveira (1991) define a Cartografia como um conjunto de operações cientíicas, artísticas e técnicas produzidas a partir de resultados de observações diretas ou de explorações de documentação, tendo em vista a elaboração de cartas, plantas e outros tipos de representação e também a sua utilização. Além desses teóricos 
e documentos oficiais, recorremos a Castellar (2005), que considera a Cartografia como uma linguagem, um sistema de código de comunicação imprescindivel em todas as esferas da aprendizagem em Geografia.

Sobre o debate em relação à Cartografia escolar e formação docente foram indispensáveis as contribuições teóricas de Almeida e Passini (1994), Castrogiovanni (2000) e Nogueira (2009), ao discutirem as dificuldades que os professores enfrentam no cotidiano da sala de aula, sobretudo a falta de recursos e o conhecimento para lhes conferir significados na prática pedagógica.

Autores que apontam caminhos e sugestões para melhor compreensão e utilização da Cartografia como recurso didático e, sobretudo, como conhecimento indispensável para ensinar e aprender a Geografia na Educação Básica, como é o caso de Almeida e Passini (1994), Almeida (2004); Castrogiovanni (2000), Martinelli (2006); Nogueira (2009); Simielli (2003) e os Parâmetros Curriculares Nacionais (1998) e que destacam a importância do estudo da linguagem cartográfica desde os anos iniciais da escolarização, foram fundamentais no processo de fundamentação e realização dessa pesquisa.

Desta forma, os vários estudos e publicações sobre a Cartografia escolar se revelam como importantes instrumentos de análise, pois tendem a potencializar o ensino e a aprendizagem geográfica, uma vez que incorporar a linguagem cartográfica no cotidiano da sala de aula é indispensável para ensinar e aprender a Geografia, cujo objeto de estudo é o espaço geográfico. Desse modo, garantir a aprendizagem da linguagem semiótica, própria da Cartografia é o ponto de partida para formar leitores e mapeadores.

\section{A cartografia na sala de aula: saberes conceituais e procedimentais}

Tendo em vista contemplar o objeto da referida pesquisa, qual seja, a alfabetização cartográfica em três escolas públicas foi necessário buscar conhecer os saberes conceituais sobre a Cartografia e os saberes procedimentais das professoras inseridas nesta investigação. Portanto, foi fundamental acompanhar as práticas desenvolvidas, assim como conhecer as trajetórias de formação e suas implicações no fazer pedagógico cotidiano.

As professoras colaboradoras ${ }^{1}$ possuem, na sua grande maioria, o curso superior em Licenciatura em Pedagogia. Das seis, apenas uma possui o Magistério a Nível Médio. Quanto ao tempo no exercício da profissão, todas possuem mais de oito anos, conforme o Quadro 1.

\begin{tabular}{|c|c|c|c|}
\hline Professor(a) & Sexo & Formação & $\begin{array}{c}\text { Tempo de exercício na } \\
\text { docência }\end{array}$ \\
\hline A & Feminino & Magistério & 9 anos \\
\hline B & Feminino & Pedagogia & 17 anos \\
\hline C & Feminino & Pedagogia & 17 anos \\
\hline D & Feminino & Pedagogia & 14 anos \\
\hline E & Feminino & Pedagogia & 15 anos \\
\hline F & Feminino & Pedagogia & 10 anos \\
\hline
\end{tabular}

Quadro 1-Perfil das Professoras Colaboradoras Fonte: Pesquisa de Campo, outubro 2010.
1 Conforme o combinado no período inicial da investigação, os nomes das colaboradoras foram mantidos em sigilo. Assim, decidimos identificá-las pelas letras iniciais do alfabeto.
Geografia Ensino \& Pesquisa, v. 16, n.1, p. 133144, jan.jun. 2012

Rios, R. B.; Souza, D. C.; Portugal, J. F.; Oliveira, S. S.

ISSN 2236- 4994 
A professora A possui formação em Magistério a nível médio e está há nove anos na docência. No ano letivo de 2010 lecionou na $4^{\text {a }}$ série $/ 5^{\circ}$ Ano do Ensino Fundamental I, priorizando o ensino das disciplinas Português e Matemática. Quando questionada sobre a contemplação dos conteúdos geográficos, a mesma informou que segue o roteiro do livro didático, reproduzindo as atividades sugeridas. Quanto aos conteúdos ligados às questões cartográficas, a professora foi enfática ao afirmar que se limita apenas a mandar as crianças a reproduzirem os mapas, como fica evidenciado no excerto da narrativa a seguir.

[...] Para mim os instrumentos cartográficos não devem ser trabalhados na $4^{\mathrm{a}}$ série $/ 5^{\circ} \mathrm{Ano}$, pois acho muito complexos para a faixa etária das crianças. Em Geografia, mando fazer pesquisas com os nomes das capitais do Brasil e descrever as paisagens durante as férias (Professora A - Escola Celso Daltro).

Infelizmente a prática da professora A contempla um ensino memorético e descritivo, não concebendo a alfabetização cartográfica como um processo que leva os estudantes a refletirem sobre o papel do mapa na construção do raciocínio espacial, buscando na Cartografia formas de entender como o espaço geográfico é construído e reconstruído.

A Professora $B$, licenciada em Pedagogia, leciona há dezessete anos. Assim como a professora A, esta profissional na sala de aula também prioriza as disciplinas Português e Matemática. No devir das observações das práticas pedagógicas empreendidas no espaço da sala de aula, ficou evidente que a mesma desenvolve um trabalho com características de um ensino considerado tradicional, não proporcionando aos alunos o desenvolvimento do senso crítico, limitando a explicação de assuntos a partir de um único referencial, qual seja, o livro didático.

Nas aulas de Geografia, a contemplação dos conteúdos geográficos também era mecanicamente reproduzida. Num certo dia, a referida docente ao trabalhar o conteúdo de orientação geográfica através dos mecanismos das rosas dos ventos, solicitou aos alunos que decorassem os nomes de todos os pontos cardeais, colaterais e subcolaterais, pois segundo a mesma, este assunto seria exigido na prova escrita do período letivo. Nota-se como "a prova, instrumento avaliativo, materializa simbolicamente a concepção de avaliação mais comum em nossas escolas" (PORTUGAL, 2005, p.127). Assim, ao ensinar os pontos de orientação, esta professora não se mostrou preocupada com a relevância desse conteúdo no processo de alfabetização cartográfica, tão importante para ler, interpretar e construir mapas, pois a Rosa dos Ventos sinalizam os pontos de referências imprescindíveis na compreensão da linguagem dos mapas.

Vale ressaltar que durante a exposição do conteúdo, a professora não fez uso de mapas para mediar o processo de ensino, dificultando a compreensão e aprendizagem dos estudantes, uma vez que a alfabetização cartográfica deve partir do mais próximo e do mais real possivel, levando-s a compreender como o espaço geográfico é construído e modificado, sendo o mapa uma das formas de representá-lo.

Sobre a questão da necessidade do uso de mapas na sala de aula, sobretudo no que concerne à abordagem de conteúdos geográficos, a professora destacou que a sua ausência é decorrente de algumas situações vivenciadas para além da sala de aula. No fragmento da sua narrativa, a seguir, a professora ressalta que não desenvolve um trabalho com mapas e nem planeja aulas práticas por que... 
[...] A escola não dispõe de recursos para se fazer um trabalho com mapas e, também, não gosto de mapas. [...] Quando estou explicando um assunto do livro didático que tem um mapa, eu não trabalho a temática que o mapa aborda, porque não domino essas questões. Não gosto de ensinar usando mapas. Durante a minha formação não tive aulas de Cartografia (Professora B - Escola Celso Daltro).

Essa narrativa da professora B sinaliza uma questão que merece destaque. Os currículos de formação de professores que devem atuar nos primeiros anos do Ensino Fundamental Licenciatura em Pedagogia, não contemplam a discussão de conteúdos voltados para a prática de ensino de Geografia, com ênfase na linguagem cartográfica. Desse modo, as dificuldades dos professores em trabalhar, no ensino, com elementos da Cartografia (mapas e suas tipologias, escalas, legendas, convenções cartográficas, coordenadas geográficas) são decorrentes das fragilidades no seu processo formativo.

Também, com dezessete anos no exercício da docência, a professora $C$ foi muito sincera ao assumir que não se sente à vontade para ensinar Geografia, pelo fato de ter que decorar várias coisas, dentre elas, os nomes de rios, estados, países, capitais, preferindo ensinar a disciplina História. Ao ser questionada sobre 0 uso da linguagem cartográfica nas suas práticas cotidianas, uma vez que a Cartografia sendo a principal linguagem gráfica da Ciência Geográfica, a mesma também se faz presente nos conteúdos curriculares da História, no âmbito da educação básica, haja vista que os fatos históricos se dão em um determinado espaço geográfico que precisa ser delimitado, visando a sua compreensão, a referida professora argumentou que só sente dificuldade no momento da exposição dos conteúdos do componente História quando os mesmos exigem a análise de mapas temáticos e históricos.

Pedagoga de formação, a professora $\mathrm{C}$, também aponta a fragilidade do seu processo formativo inicial sobre as questões que envolvem os conhecimentos da Cartografia, afirmando que ainda hoje não sabe ensinar Geografia porque não a aprendeu no seu percurso de escolarização na educação básica, bem como durante a sua formação profissional, no espaço acadêmico. Ao narrar sobre o modo como leciona os conteúdos de Geografia, afirmou utilizar-se apenas do livro didático como o único recurso didático-pedagógico.

Outra questão já sinalizada pela professora $B$, também foi mencionada pela professora $C$, quanto à exploração dos mapas que ilustram alguns temas que são abordados no livro didático de Geografia. Esta profissional reproduz a mesma prática da sua colega, desconsiderando 0 mapa como uma fonte de informações e de conhecimentos, limitando-se a contemplar apenas as descrições das paisagens e das gravuras, não tendo a preocupação de trabalhar com as noções básicas da Ciência Geográfica, tão importantes para uma compreensão crítica das relações espaciais.

O despreparo dos professores para ensinar conceitos básicos da Cartografia se reflete no aprendizado do aluno que por não dominar a técnica cartográfica, negligencia o conhecimento não transmitindo para o aluno e passando para o próximo conteúdo a ser lecionado, a partir das suas afinidades, como fica evidenciado no excerto da narrativa da professora $\mathrm{C}$.

[...] Olha meu filho (se reportando ao pesquisador) vou ser sincera, não sei trabalhar com mapas. Quando chega a essa parte do livro eu pulo e dou seqüência a outro conteúdo. Para dizer que não trabalho com mapas, mando o aluno desenhar o mapa do Brasil (Professora C - Escola Edelvira).

Geografia Ensino \& Pesquisa, v. 16, n.1, p. 133144, jan.jjun. 2012

Rios, R. B.; Souza, D. C.; Portugal, J. F.; Oliveira, S. S.

ISSN 2236- 4994 137 
Como se pode verificar, nesta narrativa, a concepção recorrente da importância da linguagem cartográfica remete apenas à reprodução de mapas. Vale, no entanto, salientar, que no campo teórico-metodológico, a Cartografia já faz parte dos conteúdos geográficos abordados nos livros didáticos. Portanto, para além da leitura de mapas e outras representações gráficas que possibilitam a compreensão de temas e conceitos geográficos, as noções básicas da Cartografia devem ser ensinadas e aprendidas ainda nos anos iniciais da escolarização. Deste modo, é compreensivel que as professoras não tenham a iniciativa para ensinar a Cartografia nos anos iniciais, pois trabalhar com os conceitos e conteúdos cartográficos não é uma tarefa fácil para quem teve fragilidade no seu processo formativo inicial, perpetuando esta lacuna na formação escolar.

Em relação à professora $D$, observou-se que é muito atenciosa com seus alunos e desenvolve atitude de afetividade com os mesmos, cujos cuidados e sentimentos são retribuídos pelos estudantes. É o tipo de professora que brinca, acalenta nos momentos adequados, porém, exige também respeito e atenção na hora da aula. Possui Licenciatura em Pedagogia, sente-se desiludida com a profissão e, por este motivo, a mesma alegou que não almeja aprender novas estratégias de ensino, tendo em vista melhorar a sua prática na sala de aula. Em relação aos conteúdos cartográficos, demonstrou que se esforça para ensinar, porém, sente dificuldade e afirmou que a principal atividade desenvolvida com seus alunos, tendo a linguagem cartográfica como tema fundante, é a maquete, concebida como um recurso para introduzir o ensino da Cartografia. Entretanto, no devir da observação da realização da referida atividade, observou-se que a noção de tridimensionalidade que a maquete representa não foi contemplada pela professora para ensinar Cartografia e favorecer a aprendizagem de um conceito relevante. Assim, podemos inferir que embora tenha a intenção de incluir um importante recurso nas suas práticas pedagógicas, no âmbito do ensino de Geografia, a professora não atentou que a maquete é um recurso que contribui para o desenvolvimento da noção de tridimensionalidade, conforme sinaliza Castrogiovanni (2000):

\begin{abstract}
A maquete é um "modelo" tridimensional do espaço. Ela funciona como um "laboratório" geográfico, onde as interações espaciais sociais do aluno no seu dia-a-dia são possíveis de serem percebidas quase na sua totalidade. A Construção da maquete é um dos primeiros passos para um trabalho mais sistematizado das representações geográficas (CASTROGIOVANNI, 2000, p.74).
\end{abstract}

Ainda, sobre a questão da Cartografia escolar, a professora $D$ enfatizou que:

[...] Domino um pouco de Cartografia... Sempre peço aos alunos que localizem o Brasil no mapa e identifiquem seus vizinhos [...] e desenvolvo também noções de direita, esquerda. Mas a escola não oferece recurso para se desenvolver um trabalho melhor, fico limitada ao quadro (Profa. D - Escola Edelvira).

Este excerto narrativo da professora D torna evidente a limitação da Cartografia escolar, não concebida no seu processo formativo, uma vez que ao utilizá-la no processo de ensino-

Geografia Ensino \& Pesquisa, v. 16, n.1, p. 133144, jan.jjun. 2012

A cartografia no/do fazer pedagógico: saberes e práticas no espaço escolar mapas pressupõe o domínio de conhecimentos básicos sobre a Cartografia Sistemática, como as noções de escalas, de coordenadas geográficas, de projeções, de articulação de cartas" (OLIVEIRA, 2010, p. 127). 
A professora $E$ é formada também em Pedagogia e atua há quinze anos no exercício da docência. Afirmou que está buscando novas metodologias, em cursos de formação continuada, visando a realização de um ensino contextualizado e com isso, garantir a aprendizagem das crianças. Durante a observação do seu fazer pedagógico, no que concerne às aulas de Geografia, ela utilizou bastante os conceitos cartográficos como orientação, através do movimento aparente do sol e atividades de elaboração de mapas mentais, buscando trabalhar os conceitos de escala e orientação espacial, a partir da descrição gráfica (desenho) do trajeto casa-escola.

Podemos dizer que através do ensino com o desenho, a "percepção e a observação da forma, surge como meio de tornar o pensamento claro e preciso e de exercitar a criança na grandeza da observação" (EBY, 1962, p. 394). De fato, o desenho é uma maneira natural da criança se expressar, bem como uma forma de representar o seu entorno, o seu espaço, uma vez que esta linguagem antecede a escrita. $O$ desenho como recurso didático facilita o registrar, a partir de suas observações cotidianas, descrevendo os lugares e os elementos da paisagem geográfica, subsidiando a aprendizagem das noções básicas da Cartografia.

Ao trabalhar com a observação do movimento aparente do sol e a inclusão do desenho, contemplando questões do cotidiano dos estudantes, ligados às concepções de orientação, localização e distâncias, a professora $E$ sinalizou que tem certa habilidade em trabalhar alguns conceitos cartográficos, necessários à construção da linguagem cartográfica e do ensino da Geografia.

Sobre a forma como aprendeu a Geografia para ministrar aulas, articulando temas desta Ciência atrelados à linguagem cartográfica no fazer pedagógico na sala de aula, a referida professora destacou que aprendeu a trabalhar com alguns recursos da Cartografia escolar, nos cursos de formação continuada, reafirmando, mais uma vez que a formação inicial de pedagogos, cuja função social dos cursos nas universidades é a preparação de professores para atuarem na educação básica, nos anos iniciais não tem garantido tais aprendizagens.

Ainda sobre a questão da importância dos conceitos da linguagem cartográfica no ensino da Geografia, a professora $\mathrm{E}$ ressaltou que:

[...] 0 processo de aprendizagem geográfica deve se preocupar com a construção de conhecimentos conceitos/noções junto aos educandos, não atrelando ao seu ensino a memorização, mas com uma visão geográfica que transcende a sala de aula e passa a fazer parte da realidade do aluno (Profa E - Escola João Paulo II).

Este fragmento da narrativa da professora $\mathrm{E}$, sinaliza a necessidade de desenvolver um trabalho que contemple uma discussão que parta do mais próximo, do mais real possível do espaço de vivência do aluno para ter aprendizagem significativa.

A professora $F$ iniciou a sua trajetória de formação para o exercício da docência no curso de Licenciatura em História, abandonando-o no $6^{\circ}$ semestre, escolhendo, por substituição, 0 curso de Licenciatura em Pedagogia. Especialista em Psicopedagogia e em Educação Especial, há dez anos exerce a profissão e destaca que na sua prática pedagógica é dada grande relevância aos elementos cartográficos, articulando-os com a realidade dos seus alunos. A professora em questão destaca o trabalho desenvolvido com mapas para crianças com deficiência intelectual, tendo na sua prática docente cotidiana, a realização de atividades que despertam nos alunos a apreensão do mundo como um todo, facilitando a compreensão da realidade em que vivem, articulado com os conceitos cartográficos. Sobre esta discussão, a mesma evidencia que:

\author{
Geografia Ensino \& Pesquisa, v. 16, n.1, p. 133- \\ 144, jan./jun. 2012 \\ Rios, R. B.; Souza, D. C.; Portugal, J. F.; \\ Oliveira, S.S. \\ ISSN 2236- 4994


[...] A alfabetização cartográfica nos anos iniciais visa fundamentalmente desenvolver e aplicar a linguagem gráfica que organize passo a passo, a apreensão do espaço vivido pelo aluno e que o habilite a construir conceitos geográficos indispensáveis ao seu desenvolvimento cognitivo no âmbito das relações de orientação, localização e representações (Profa F - Escola João Paulo II).

Mesmo sem a formação específica em Geografia, a professora $F$, neste excerto da sua narrativa, destaca a importância da alfabetização e da linguagem cartográficas para aprender conceitos e temas geográficos nos anos iniciais, garantindo também essas noções para os estudantes com deficiência intelectual, preocupação esta, muitas vezes negada à maioria das crianças "ditas normais" nesta fase da escolaridade.

Questionada sobre a importância dada à alfabetização cartográfica, para esse grupo específico de estudantes, a professora salientou que o trabalho prático com recursos cartográficos - mapas adaptados, maquetes construídas pelos próprios alunos, computador, globo - favorece a aquisição dos conceitos espaciais (lateralidade, distância, localização, proporção, etc).

Com o propósito de contextualizar o que a professora diz fazer e o que faz, descreveremos uma prática assistida, no devir das observações e que, de fato, demonstra o envolvimento, 0 preparo técnico e a definição dos objetivos didático-pedagógicos da professora $F$, ao planejar e executar uma tarefa que caracteriza uma prática de alfabetização cartográfica. 0 trabalho começou assim: a professora solicitou que uma criança deitasse no papel metro estendido no chão da sala e a professora fez o contorno do seu corpo. A partir daí a professora pediu à criança que completasse 0 desenho com as características/detalhes que faltavam, por exemplo, os olhos, a boca, o nariz, os cabelos e até os acessórios utilizados pela própria criança. Esta prática intenciona, segunda a professora, a representação delimitada de um espaço, e, a partir da apreensão do espaço do seu corpo, a criança é desafiada a ampliar as suas percepções para ambientes significativos do seu cotidiano: a sala de aula, a escola, o quarteirão da escola, o seu quarto, a sua casa e, posteriormente, o percurso casa-escola.

Ao ser indagada sobre a relevância da atividade retratada, a professora $\mathrm{F}$ afirmou que a sua preocupação em desenvolver diferentes estratégias para garantir a alfabetização cartográfica está vinculada a outras questões consideradas necessárias para o desenvolvimento cognitivo das crianças. Assim, a professora narrou:

Esse trabalho de conhecimento do corpo parte do desejo de possibilitar às crianças o desenvolvimento da capacidade cognitiva, com implicações, também na área da linguagem, da escrita, da resolução de problemas e, sobretudo, do exercício da memorização, que para as crianças com deficiência intelectual, torna-se extremamente necessária, pois as mesmas não possuem a habilidade de arquivar informações e dados (Profa F - Escola João Paulo II).

Neste excerto da narrativa, a professora $F$ sinaliza a importância da aprendizagem das noções básicas da Cartografia, tendo em vista garantir a competência da leitura de mapas que perpassa pela decodificação dos significantes (os símbolos) e os respectivos significados (a mensagem) dos signos representados que são os elementos que compõem a legenda.

Geografia Ensino \& Pesquisa, v. 16, n.1, p. 133 


\section{A cartografia do fazer pedagógico: algumas considerações, quase finais}

A partir das observações em campo, das entrevistas realizadas e da aplicação de questionários, com o objetivo de conhecer e analisar as práticas de alfabetização cartográfica empreendidas pelas professoras nos anos iniciais podemos fazer algumas inferências sobre as práticas desenvolvidas por seis professoras que lecionam em escolas públicas municipais, situadas no bairro da Queimadinha, na cidade de Feira de Santana - Bahia, sobre o trabalho empreendido com a utilização da linguagem cartográfica no ensino da Geografia.

A primeira inferência diz respeito à formação acadêmica de pedagogos. Conforme sinalizado pelas próprias professoras, a formação inicial não garante a construção de conhecimentos da Ciência Geográfica e da sua principal linguagem gráfica, qual seja, a Cartografia necessários à prática educativa, ou seja, o exercício da docência nos anos iniciais da educação básica. Ou seja, as professoras não aprenderam a trabalhar com este importante recurso, portanto, não sabem e não conseguem ensinar.

Os saberes disciplinares da Geografia devem ser construídos nos cursos de formação inicial, tendo em vista a qualificação do profissional para o exercício da docência, considerando os referenciais e os currículos escolares nesta etapa da escolarização básica, uma vez que 0 ensino de Geografia requer diversas linguagens por meio das quais os alunos entram em contato com o saber sistematizado, tendo a Cartografia, como eixo fundante para ensinar e aprender os conceitos e habilidades relacionadas à representação espacial, a partir das noções básicas, tais como 0 alfabeto cartográfico, ponto, linha e área, juntamente com a construção da noção de legenda, proporção e escala necessárias para a orientação espacial. Desse modo, a prática docente contribui, significativamente, para a alfabetização cartográfica dos estudantes implicando também, para além da leitura e interpretação de mapas, na apreensão de outras linguagens, como imagens, gráficos, tabelas nas aulas de Geografia e outros componentes do currículo.

A segunda inferência versa sobre os recursos cartográficos utilizados nas aulas de Geografia. Do universo das professoras, colaboradoras da pesquisa, 50\% (cinquenta por cento) alegaram que sempre usam o mapa de acordo à necessidade do conteúdo; 17\% (dezessete por cento) responderam que nunca utilizam e $33 \%$ (vinte por cento) às vezes. Contudo, durante a realização da investigação, em campo, percebemos que as respostas apontadas no questionário não retratam, de fato, às práticas desenvolvidas, no cotidiano da sala de aula.

Desse modo, as professoras que afirmaram não utilizar os recursos cartográficos no seu fazer pedagógico cotidiano são justamente as mesmas que evidenciaram ter muita dificuldade no trato com os conteúdos geográficos. Este fato é resultante de uma formação docente que não contemplou os conteúdos e saberes necessários à alfabetização cartográfica, cujas habilidades são tão essenciais para o processo de ensino-aprendizagem.

Para trabalhar com os instrumentos cartográficos em sala de aula, como globos, mapas, atlas, maquetes, fotografias, plantas, cartas é necessário que o professor tenha um domínio conceitual e procedimental, ou seja, o saber-fazer, planejando atividades considerando a realidade dos estudantes, respeitando a faixa etária e o desenvolvimento cognitivo das crianças, articulando conceitos fundamentais e básicos para a apreensão e 0 processamento de informações, culminando na produção de conhecimentos.

Gradualmente o domínio das operações espaciais topológicas como a localização dos objetos, sem considerar a distância, reta, nem ângulos e os pontos de referências elementares

Geografia Ensino \& Pesquisa, v. 16, n.1, p. 133144, jan.jun. 2012

Rios, R. B.; Souza, D. C.; Portugal, J. F.; Oliveira, S. S.

ISSN 2236- 4994 
como perto, longe, dentro, fora, em cima, embaixo, são essenciais para termos bons encaminhamentos no que concerne à alfabetização cartográfica, cujas atividades são responsáveis para a formação de bons leitores e mapeadores conscientes, haja vista que a criança localiza objetos ou pessoas de acordo com o ponto de vista dela ou referencial adotado, tornando mais fácil, de fato, a localização a partir do seu próprio referencial. Partindo dessas práticas, as crianças poderão assimilar noções de orientação mais complexas, passando a entender os mecanismos dos pontos cardeais, do movimento aparente do Sol (Leste - Oeste), dos sistemas de coordenadas geográficas, da compreensão dos diferentes fusos horários e de como os diferentes objetos se distribuem e se organizam no espaço geográfico, podendo assim correlacionar o seu comportamento espacial aos condicionantes ambientais, físicos e humanos na superfície terrestre.

Dessa maneira, conduzindo a aprendizagem das crianças a uma percepção e compreensão da organização espacial, proporcionando maior conscientização dos seus processos mentais, que por vez contribuem de forma plena para a formação de leitores/mapeadores críticos, capazes de analisar e interpretar o espaço à sua volta e não apenas reprodutores de mapas disponíveis nos livros didáticos.

O domínio espacial, através da linguagem cartográfica deve ser desenvolvido nas escolas, assim como o domínio da língua escrita, do raciocínio matemático e do pensamento cientííco, pois, "[...] preparar o aluno para essa leitura deve passar por preocupações metodológicas tão sérias quanto à de se ensinar a ler e escrever, contar e fazer cálculos matemáticos" (ALMEIDA e PASSINI, 1994, p. 15).

A terceira inferência perpassa pela concepção de educação cartográfica como um processo de construção de estruturas e conhecimentos que favorecem a leitura e interpretação de mapas, desde os anos iniciais, pois a linguagem cartográfica é considerada como um instrumento essencial para a representação do espaço geográfico, de seus elementos e suas relações, sendo importante no processo de ensino dos conteúdos geográficos para as crianças e para tal o professor deve estar atento e, ao mesmo tempo, qualificado para trabalhar o processo de comunicação que irá resultar numa eficiente utilização do mapa em sala de aula. No entanto, o despreparo técnico das professoras em relação ao ensino de conteúdos cartográficos é preocupante, como ficou sinalizado nesta pesquisa.

De acordo com as observações das práticas desenvolvidas pelas professoras e as respostas registradas nos questionários, além da análise das narrativas gravadas fica evidente uma fragilidade dos conhecimentos geográficos, em geral e cartográfico, em especial, dos profissionais. Essa fragilidade que acarreta distorções no uso dos documentos cartográficos como meio de comunicação. Tais observações levam-nos a fazer o seguinte questionamento: Como pode o professor ensinar Cartografia escolar se o mesmo constitui-se num conhecimento que não adquiriu durante a sua formação?

É primordial que os mapas façam parte da sala de aula como um suporte metodológico, não podendo estar apenas enrolados e/ou guardados nos armários instalados na sala da diretoria das escolas desmistificando alguns equívocos na leitura e interpretação dos mesmos, uma vez que representam os elementos físicos, humanos e econômicos reais de uma dada região ou país possibilitando uma análise e interpretação espacial, que facilita o planejamento e mudanças nas ações políticas e econômicas. Vale ressaltar que os mapas contêm um conjunto de conhecimento que podem ser utilizados como instrumento educacional, político, econômico, militar, entre outros. 
Enfim, as conclusões dessa pesquisa não devem ser pensadas isoladamente, perpassam por vários fatores, como a falta de preparo do professor em utilizar os conceitos cartográficos, bem como a disponibilidade desses recursos nas unidades escolares.

A pesquisa evidenciou a fragilidade da maioria das professoras dos anos iniciais no que concerne à utilização de mapas em sala de aula, resultante de uma formação inicial deficitária que não contemplou essas discussões no seu processo formativo. Ficou claro também que as professoras não buscam qualificação para utilizar melhor esses elementos cartográficos associado ao ensino de temas e conceitos da Geografia, tratados de forma fragmentada, como sinalizamos antes.

Contudo, vale destacar que a escola João Paulo Il, acompanhamos um importante trabalho sobre a alfabetização cartográfica para crianças com necessidades especiais. Essa unidade escolar prima por uma proposta de ensino voltada para a alfabetização cartográfica. Entretanto, a referida escola não difere das outras duas, lócus, também da pesquisa no que concerne à falta de recursos cartográficos, mas as duas professoras investigadas buscam alternativas para suprir essa carência.

A inserção da leitura de mapas, gráficos e tabelas no contexto do ensino de temáticas da Geografia Escolar tão recorrente nos livros didáticos de Geografia, tem sido um avanço na produção deste material didático, tratando dados e informações geográficas atuais e contextualizadas. Entretanto, lidar com essas informações no contexto escolar ainda, nos dias atuais, tem sido um dos maiores problemas apontados por professores que lecionam nas classes dos anos iniciais.

\section{Referências}

ALMEIDA, Rosangela Doin de; PASSINI, Elza Yasuko. 0 espaço geográfico: ensino e representação. 5. ed. São Paulo: Contexto, 1994.

ALMEIDA, Rosangela Doin Almeida de. (Org.). Cartografia Escolar. São Paulo: Contexto, 2004.

BRASIL. Secretaria da Educação Fundamental. Parâmetros Curriculares Nacionais: Geografia. Brasília: Secretaria da Educação Fundamental MEC/SEF, 1998.

CASTELLAR, Sonia. Educação geográfica: teorias e práticas docentes. São Paulo: Contexto, 2005.

CASTROGIOVANNI, Antonio Carlos. Apreensão e compreensão do espaço geográfico. In: CASTROGIOVANNI, Antonio Carlos; CALLAl, Helena C; KAERCLER, Nestor André. Ensino de Geografia: práticas e textualizações no cotidiano. Porto Alegre: Mediação, 2000.

EBY, Frederick. História da Educação Moderna. Teoria, Organização e Práticas Educacionais. Tradução de Maria Ângela Vinagre de Almeida, Nelly Aleotti Maia, Malvina Cohen Zaide. Porto Alegre: Globo; Brasília: INL, 1962.

MARTINELLI, Marcelo. Mapas de geografia e Cartografia temática. São Paulo: Contexto, 2006.

NOGUEIRA, E. Ruth (Org.). Espaços para visuais e invisuais. Florianópolis: [s.n], 2009.

OLIVEIRA, C. Curso de Cartografia moderna. Rio de Janeiro: IBGE, 1991.

OLIVEIRA, Ivanilton José de. A Cartografia na Formação do professor de Geografia: análise da rede pública municipal de Goiânia. In: MORAIS, Eliana Marta Barbosa de; MORAES, Loçandra Borges de. Formação de Professores: conteúdos e metodologias no ensino de Geografia. Goiânia: Editora Vieira, 2010.

Geografia Ensino \& Pesquisa, v. 16, n.1, p. $133-$ 144, jan.jun. 2012

Rios, R. B.; Souza, D. C.; Portugal, J. F.; Oliveira, S. S. 
PASSINI, Elza Yasuko; PASSINI, Romão; MALYSZ, Sandra T. Prática de ensino de Geografia e estágio supervisionado. São Paulo: Contexto, 2007.

PORTUGAL, Jussara Fraga. Práticas avaliativas no ensino fundamental: entre o dizer e o fazer no cotidiano da sala de aula. 2005. 251 f. Dissertação (Mestrado - Programa de Pós-Graduação em Educação e Contemporaneidade) Universidade do Estado da Bahia - UNEB: Salvador, 2005.

SIMIELLI, Maria Elena Ramos. Cartografia no Ensino Fundamental e Médio. In: CARLOS, Ana Fanni Alessandri et al. (Orgs.). A Geografia na sala de aula. 3. ed. São Paulo: Contexto, 2003.

\section{Correspondência:}

Ricardo Bahia Rios - Rua das Araras, SN, Bl.12, Ap.704 - Resd. Pq. do Imbuí - Imbuí. CEP.41720-010. Salvador-Bahia

E-mail: rrbahia79@yahoo.com.br

Recebido em 14 de julho de 2011

Revisado pelo autor em 18 de outubro de 2011

Aceito em 16 de novembro de 2011 